\title{
IMPLEMENTASI PARENTING EDUCATION UNTUK MENINGKATKAN PARENTING SKILLS ORANG TUA ANAK TUNARUNGU DI KB-TK INKLUSIF AURICA SURABAYA
}

\author{
Drs. Ahmad Fachrurazi, M.Pd* \\ Dian Puspa Dewi, S.Pd., M.Pd. * \\ Ana Rafikayati, S.Pd., M.Pd ** \\ *Dosen Program Studi PG-PAUD \\ ***Dosen Program Studi Bimbingan Konseling \\ Universitas PGRI Adi Buana Surabaya.
}

\begin{abstract}
ABSTRAK
Parenting education dberikan pada orangtua untuk memberikan informasi terkait paretning skiils anak tunarungu. Tujuan dari penelitian ini adalah untuk mengetahui apakah implementasi parenting education dapat meningkatkan parenting skills orang tua anak tunarungu di KB-TK Inklusi Aurica Surabaya dan mendeskripsikan peningkatan parenting skills orang tua anak tunarungu setelah implementasi parenting education di KB-TK Inklusi Aurica Surabaya.

Pendekatan penelitian yang digunakan dalam penelitian ini adalah pendekatan kualitatif dengan jenis penelitian tindakan (action research).Dalam penelitian tindakan ini penelitian dilaksanakan dalam 2 siklus. Siklus terdiri dari 4 langkah, yaitu: (1) perencanaan (planning), (2) pelaksanaan (acting), (3) pemantauan (monitoring atau observing), dan (4) penilaian (reflecting atau evaluating). Teknik pengumpulan informasi menggunakan teknik tes tulis pada materi karakteristik dan tahapan perkembangan anak tunarungu, dan tes kinerja (praktik) pada materi carara berkomunikasi dengan anak tunarungu. Analisis informasi yang digunakan adalah analisis data kualitatatif yang dilandasi oleh hasil dari setiap tindakan. Kriteria keberhasilan ketuntasan di dalam penelitian ini adalah $85 \%$.

Berdasarkan hasil penelitian yang telah dilakukan, dapat disimpulkan bahwa implementasi parenting education dapat meningkatkan kemampuan parenting skills orang tua anak tunarungu di KB/TK Inklusi Aurica Surabaya. Hal tersebut dapat ditunjukan dengan hasil rata-rata perolehan nilai siklus I sebesar 67, 43 sedangkan nilai ketuntatasan minimal klasikal sebesar 46,67 \%. Sedangkan hasil rata-rata perolehan nilai siklus II sebesar 72, 46 sedangkan nilai ketuntasakan klasikal adalah $86,67 \%$.
\end{abstract}

Kata Kunci : Parenting Education, Orangtua Anak Tunarungu, Parenting skills

\section{A. Pendahuluan}

Parenting adalah salah satu tugas yang paling penting bagi keluarga. Orangtua adalah kunci untuk penyediaan rasa aman, pengasuhan dan lingkungan pembelajaran yang positifuntuk anak-anak saat mereka tumbuh dan berkembang. Dengan 
demikian, orangtua harus memiliki pengetahuantertentu, keterampilan, sikap dan kemampuan interpersonal sebagai orangtua yang efektif. Adapun kemampuan tersebut dikenal secara luas dengan parenting skills.

Orangtua harus memiliki parenting skills yang baik agar dapat memantau perkembangan anak tunarungu yang memiliki tahapan perkembangan berbeda dengan anakanak pada umumnya. Meskipun begitu, lebih dari $90 \%$ anak tunarungu lahir di keluarga yang stres. Hal ini bukan hanya karena kehadiran anak tunarungu di keluarga, tetapi juga karena kebutuhan khusus dari anak tunarungu (Feher, 1996). Pada umumnya orangtua bingung dalam membesarkan dan mengasuh anak tunarungu.

Zepeda dkk (2004:8) menyatakan bahwa banyak orangtua anak tunarungu merasa kesulitan dalam memahami ketunarunguan anak mereka dan butuh lebih banyak informasi tentang karakteristik anak, perkembangan anak dan cara berkomunikasi dengan anak. Hal ini diperkuat dengan hasil angket yang diberikan kepada orangtua siswa tunarungu di KB-TK Inklusi Aurica
Surabaya. Dari 30 orangtua, yang menyatakan pada $80 \%$ mengalami kesulitan dalam mengenal karekteristik anak yang berbeda dengan anak-anak pada umumnya, 90\% bingung tentang cara berkomunikasi dengan anaknya dan 93\% merasa tidak percaya diri dalam membesarkan anak mereka.

Parenting education diharapkan dapat menjadi solusi dalam meningkatkan parenting skills orangtua anak tunarungu. Furlong dkk 2000 dalam Van Ryzin dkk (2016:43) memaparkan bahwa parenting education berbasis kelompok efektif dalam meningkatkan parenting skills dan meningkatkan kesehatan mental orangtua. Sedangkan Thomas \& Zimmer-Gembeck (2007) lebih jauh menjelaskan bahwa hasil dari mengikuti program parenting education antara lain adalah meningkatnya keyakinan diri orangtua, kehangatan orangtua kepada anaknya, mengurangi tekanan/ stres orangtua dan meningkatnya keterampilan pengasuhan atau parenting skills yang positif orang tua kepada anaknya.

Adapun tujuan penelitian dalam penelitian ini adalah sebagai berikut; 
(a) Mengetahui apakah implementasi parenting educationdapat meningkatkan parenting skills orang tua anak tunarungu di KB-TK Inklusi Aurica Surabaya, dan (b) Mendeskripsikan peningkatan parenting skills orang tua anak tunarungu setelah implementasi parenting education di KB-TK Inklusi Aurica Surabaya.

\section{B. Metode Penelitian}

Pendekatan penelitian yang digunakan dalam penelitian ini adalah pendekatan kualitatif dengan jenis penelitian tindakan (action research). Penelitian tindakan ini direncanakan dilaksanakan dalam 2 siklus. Waktu tersebut dianggap relevan dalam mencapai hasil yang diinginkan dalam meningkatkan parenting skills orangtua anak tunarungu. Siklus terdiri dari 4 langkah, yaitu: (1) perencanaan (planning), pelaksanaan (acting), (3) pemantauan (monitoring atau observing), dan (4) penilaian (reflecting atau evaluating).

Informasi yang dikumpulkan dalam penelitian ini adalah parenting skills orang tua anak tunarungu. Adapun parenting skills yang menjadi fokus adalah 3 parenting skills dasar yang dibutuhkan dalam mengasuh anak tunarungu yaitu, (1) pemahaman karakteristik anak tunarungu, (2) pemahaman tahapan perkembangan anak tunarungu, dan (3) kemampuan berkomunikasi dengan anak tunarungu.

Teknik pengumpulan informasi yang digunakan adalah teknik tes tulis pada materi karakteristik dan tahapan perkembangan anak tunarungu, dan tes kinerja (praktik) pada materi carara berkomunikasi dengan anak tunarungu.

Kriteria keberhasilan ketuntasan di dalam penelitian ini adalah $85 \%$. Dengan demikian dapat disimpulkan bahwa jika hasil ketuntasan $\geq 85 \%, \quad$ maka implementasi parenting educationdinyatakan dapat meningkatkan parenting skills orang tua anak tunarungu di KB-TK Inklusi Aurica Surabaya.

\section{Hasil Penelitian Dan Pembahasan}

Penelitian dilakukan di KB/TK Inklusi Aurica Surabaya, dengan subjek penelitian seluruh orang tua sebanyak 30 orang. Sebelum melakukan implementasi 
parenting education terlebih dahulu dilakukan pratindakan atau Pre test. Hasil yang diperoleh pada kegiatan prra tindakan ini adalah bahwa terdapat 4 orang tua yang mencapai ketuntasan minimal 70 atau sebesar $13,33 \%$. Sedangkan sisanya 26 orang tua belum mencapai ketuntasan minimal 70 atau sebesar $86,67 \%$. Oleh karena itu, maka dapat diketahui bahwa ketuntasan klasikal $85 \%$ yang telah tidak tercapai.

Data yang diperoleh dari kegiatan pra tindakan ini menjadi dasar peneliti melakukan tindakan parenting education pada siklus I. Kegiatan parenting pada siklus I dilakukan selama 9 kali pertemuan dengan rincian, 3 kali pemberian materi karakteristik anak tunarungu, 3 kali pemberian materi tahap perkembangan anak tunarungu dan 3 kali pertemuan tentang materi komunikasi dengan anak tunarungu. Pemberian kegiatan parenting selama $2 \times 35$ menit.

Hasil perolehan siklus I bahwa terdapat 14 orang tua yang memperoleh nilai hasil tes sesuai dengan ketuntasan minimal 70 atau sebesar 46,67\%. Sedangkan sisanya sebanyak 16 orang tua memperoleh nilai hasil tes di bawah ketuntasan minimal 70 atau sebesar 53,3\%. Siklus I belum dapat mencapai ketuntasan minimal individual sebesar 70 dan ketuntasan minimal secara klasikal yaitu sebesar $85 \%$. Oleh karena itu, diperlukan adanya siklus II. Hal ini sebagai upaya untuk mencapai tujuan penelitian yaitu meningkatkan parenting skills orangtua anak tunarungu dengan mengimplementasikan parenting education.

Kegiatan parenting dilakukan selama 3 kali pertemuan dengan rincian. Pemberian kegiatan parenting selama 2 x 35 menit. Berdasarkan data yang telah dipaparkan di atas, dapat dilihat bahwa terdapat 26 orang tua yang memperoleh nilai hasil tes sesuai dengan ketuntasan minimal 70 atau sebesar 86,67 \%. Sedangkan sisanya sebanyak 4 orang tua memperoleh nilai hasil tes di bawah ketuntasan minimal 70 atau sebesar 13,3\%. Berdasarkan pemaparan hasil tersebut dapat disimpulkan bahwa pada Siklus II sudah mencapai ketuntasan minimal individual sebesar 70 dan ketuntasan minimal secara klasikal yaitu sebesar $85 \%$. 
Setelah tindakan yang diimplementasikan pada siklus I dan siklus II maka diperoleh jawaban atas rumusan masalah dalam penelitian ini. Seperti yang diketahui bahwa anak tunarungu tidak hanya hadir dalam usia dewasa namun juga pada anak usia dini. Orang tua yang memiliki anak tunarungu pada usia dini mayoritas memiliki kesulitan dalam komunikasi dengan anak mereka. Mereka cenderung tidak mampu memahami apa yang dimaksud oleh anak dalam ekspresinya, terlebih mereka mengingat bahwa sebagai tempat yang pertama kali untuk belajar maka orang tua harus mampu berkomunikasi dengan anak mereka yang memiliki hambatan pendengaran. Sehingga setelah diimplementasikan kegiatan parenting education ini memiliki banyak sekali manfaat. Hal ini berdasarkan komentar dan saran dari para orang tua yang mengikuti kegiatan parenting. Orang tua memperoleh informasi yang beragam tentang bagaimana dengan anak mereka yang memiliki hambatan pendengaran.

Seperti yang disampaikan oleh Thomas \& Zimmer-Gembeck (2007) menjelaskan hasil penelitiannya adalah orangtua yang mengikuti program parenting education mengalami perubahan yang positif antara lain adalah meningkatnya keyakinan diri orangtua, kehangatan orangtua kepada anaknya, mengurangi tekanan/ stres orangtua dan meningkatnya ketrampilan pengasuhan atau parenting skills yang positif dari orang tua kepada anaknya.

\section{Penutup}

\section{Kesimpulan}

Berdasarkan tindakan yang telah dilakukan dalam penelitian ini yaitu parenting education kepada orang tua anak tunarungu di KB-TK Inkusi Aurica Surabaya diperoleh kesimpulan bahwa implementasi parenting education dapat meningkatkan kemampuan parenting skills orang tua anak tunarungu di KB/TK Inklusi Aurica Surabaya. Hal tersebut dapat ditunjukan dengan peningkatan pemahaman dan kemampuan anak tunarungu dari siklus I hingga siklus II. Adapun rincian hasil tersebut adalah ratarata perolehan nilai siklus I sebesar 67, 43 sedangkan nilai ketuntatasan minimal klasikal 
sebesar 46,67\%. Berdasarkan data tersebut, maka direncanakan pelaksanaan siklus II. Hasil ratarata perolehannya adalah sebesar 72, 46 sedangkan nilai ketuntasakan klasikal adalah 86,67 $\%$.

\section{Saran}

Berdasarkan hasil penelitian di atas, peneliti menyarankan beberapa hal kepada pihak berikut:

a. Bagi orang tua:

1) Hal ini dikhususkan bagi orang tua yang memiliki anak tunarungu sebaiknya aktif dalam mencari informasi tentang bagaimana penagsuhan kepada anak mereka baik mengikuti kegiatan parenting, diskusi dengan ahli dan mencari informasi melalui media massa atau sosial media,

2) Sebaiknya tidak memaksa anak mereka yang mengalami hambatan pendengaran agar sama dengan anak lainnya yang normal

b. Bagi sekolah

Semakin banyak fasilitas yang diberikan kepada orang tua dalam memperoleh infromasi pengasuhan bagi anak mereka yang mengalami hambatan pendengaran

c. Bagi peneliti selanjutnya

Melakukan penelitian tentang penerapan parenting education pada permasalahan anak berkebutuhan khusus yang lainnya. Karena masih sangat banyak permasalahan anak berkebutuhan khusus yang bersumber dari orang tua.

\section{Daftar Pustaka}

Bailey, perkins \& wilkins.1995. Parenting Skillss Workshop Series, A. Manual for Parent Educators. Journal. A. Cornell Cooperative Extension Publication.

Brereton,Avril V. 2009. Autism Spectrum Disorders Parent education and skillss training: a practical and effective way to help.Monash University: ACT-NOW Fact Sheet 50.

Brown, MB. 2000. Recommended Practices: Parent Education and Support. (Online), (http://ag.udel.edu/extension/fam/ best/crp-part 100.htmldiakses 16 Desember 2015).

Estabrooks. W. 1994. Auditory Verbal Therapy For Parents And Professionals. Washington DC, U.S.A. :Alexander Graham Bell Association for the deaf. 
Feher, Terri. 1996. Stress and Coping in Families with Deaf Children. Journal of Deaf Studies and Deaf Education Vol 1 (3): 155-166.

Feldman \& Werner.2002.The Development of A Family Life Education Manual for Teaching Parenting Skillss to Incarcerated Fathers.Dissertation. Miami University.

Gargiulo, Richard M. 2012. Speial Education in Contemporary Society: An Introduction to Exceptionality $4^{\text {th }}$ ed. California: Sage Publication.Inc.

Hasan, M. 2011. Pendidikan Anak Usia Dini. Diva Press: Yogyakarta

Hotchkiss, Jacqueline Suzanne., Biddle, Kimberly dan Sacramento. 2009. Implementing parenting education policy to overcome parental stress and foster educational andbehavioral competence in children. California: California State University

Jehan, Bani Fauziyah. 2014. Efektivitas Kegiatan Parenting Skillss dalam Pemberdayaan Keluarga Anak Jlanan di Pusat Pengembangan Pelayanan Sosial Anak atau Social Development centre fo Children (SDC).Jakarta: Naskah publikasi Program studi Kesejahteraan sosial UIN Syarif Hidayatullah Jakarta

Mukni'ah. 2014. Parenting Skillss sebagai Upaya Meningkatkan Akhlak Mulia bagi Anak padaMasa Pendidikan Dasa. Jakarta: Maktabah al- Tarbiyyah Liduwali
al-Khalij. Direktorat Pendidikan Anak Usia Dini. 
8 - Helper, Vol 34 No 2 (2017) 